\title{
Development of Supersonic Retro-Propulsion for Future Mars Entry, Descent, and Landing Systems
}

\author{
Karl T. Edquist ${ }^{*}$ and Artem A. Dyakonov ${ }^{\dagger}$ \\ NASA Langley Research Center, Hampton, Virginia, 23681 \\ Jeremy D. Shidner ${ }^{\dagger}$ \\ Analytical Mechanics Associates, Inc., Hampton, Virginia, 23681 \\ Joseph W. Studak ${ }^{\star}$ and Michael A. Tigges ${ }^{\S}$ \\ NASA Johnson Space Center, Houston, Texas, 77058 \\ Devin M. Kipp" and Ravi Prakash \\ NASA Jet Propulsion Laboratory, Pasadena, California, 91109 \\ Kerry A. Trumble \\ NASA Ames Research Center, Moffett Field, California, 94035 \\ Ian C. Dupzyk ${ }^{* *}$ \\ ELORET Corporation, Sunnyvale, California, 94087 \\ Ashley M. Korzun ${ }^{\dagger \dagger}$ \\ Georgia Institute of Technology, Atlanta, Georgia, 30332
}

\begin{abstract}
Recent studies have concluded that Viking-era entry system technologies are reaching their practical limits and must be succeeded by new methods capable of delivering large payloads (> 10 metric tons) required for human exploration of Mars. One such technology, termed Supersonic Retro-Propulsion, has been proposed as an enabling deceleration technique. However, in order to be considered for future NASA flight projects, this technology will require significant maturation beyond its current state. This paper proposes a roadmap for advancing the component technologies to a point where Supersonic RetroPropulsion can be reliably used on future Mars missions to land much larger payloads than are currently possible using Viking-based systems. The development roadmap includes technology gates that are achieved through testing and/or analysis, culminating with subscale flight tests in Earth atmosphere that demonstrate stable and controlled flight. The component technologies requiring advancement include large engines capable of throttling, computational models for entry vehicle aerodynamic/propulsive force and moment interactions, aerothermodynamic environments modeling, entry vehicle stability and control methods, integrated systems engineering and analyses, and high-fidelity six degree-offreedom trajectory simulations. Quantifiable metrics are also proposed as a means to gage the technical progress of Supersonic Retro-Propulsion. Finally, an aggressive schedule is proposed for advancing the technology through sub-scale flight tests at Earth by 2016.
\end{abstract}

\footnotetext{
*Aerospace Engineer, Atmospheric Flight \& Entry Systems Branch, MS 489, Karl.T.Edquist@nasa.gov, Senior Member.

$\dagger$ Aerospace Engineer, Atmospheric Flight \& Entry Systems Branch, MS 489, Member.

$\$$ Propulsion Systems Engineer, Propulsion Systems Branch, MS EP4.

$\S$ Senior Engineer, Aeroscience \& Flight Mechanics Division, MS EG5, Member.

I Systems Engineer, Entry, Descent, and Landing Systems and Advanced Technologies Group, MS 321-220

${ }^{\#}$ Research Scientist, Aerothermodynamics Branch, MS 230-2, Member.

** Aerospace Engineer, Systems Analysis Branch, MS 258-1, Member.

i† Graduate Research Assistant, Daniel Guggenheim School of Aerospace Engineering, Student Member.
} 


\section{Nomenclature}

\section{Symbols}

$\begin{array}{ll}\text { A } & \text { area }\left(\mathrm{m}^{2}\right) \\ \mathrm{C} & \text { force coefficient, } \mathrm{F} / \mathrm{q}_{\infty} \mathrm{A}_{\text {ref }} \\ \mathrm{L} / \mathrm{D} & \text { lift-to-drag ratio } \\ \mathrm{T} & \text { thrust }(\mathrm{N}) \\ \mathrm{T} / \mathrm{W} & \text { thrust-to-weight ratio } \\ \mathrm{V} & \text { velocity } \\ \mathrm{m} & \text { mass }(\mathrm{kg}) \\ \mathrm{p} & \text { pressure }(\mathrm{Pa}) \\ \mathrm{q} & \text { dynamic pressure, } \rho \mathrm{V}^{2} / 2(\mathrm{~Pa}) \\ \beta_{\mathrm{m}} & \text { ballistic coefficient, } \mathrm{m} / \mathrm{C}_{\mathrm{D}} \mathrm{A}_{\text {ref }}\left(\mathrm{kg} / \mathrm{m}^{2}\right)\end{array}$

Acronyms

$\begin{array}{ll}\text { BLST } & \text { Balloon Launched SRP Test } \\ \text { CFD } & \text { Computational Fluid Dynamics } \\ \text { COPV } & \begin{array}{l}\text { composite overwrapped pressure vessel } \\ \text { DOF }\end{array} \\ \text { degrees of freedom } \\ \text { DRA5 } & \begin{array}{l}\text { Design Reference Architecture } 5.0 \\ \text { entry, descent, and landing }\end{array} \\ \text { EDL } & \text { Exploration Technology Development } \\ \text { ETDP } & \begin{array}{l}\text { Program } \\ \text { guidance, navigation, and control }\end{array}\end{array}$

\author{
ISRU in-situ resource utilization \\ KPP Key Performance Parameter \\ MER Mars Exploration Rover \\ MSL Mars Science Laboratory \\ RCS reaction control system \\ SRP Supersonic Retro-Propulsion \\ SRST Sounding Rocket SRP Test \\ TPS thermal protection system \\ TRL Technology Readiness Level
}

\section{Subscripts}

$\begin{array}{ll}\text { A } & \text { axial } \\ \mathrm{D} & \text { drag } \\ \mathrm{N} & \text { normal } \\ \mathrm{T} & \text { thrust } \\ \text { ref } & \text { reference } \\ \infty & \text { freestream condition }\end{array}$

\section{Introduction}

Starting with the two Viking landers in 1976 and continuing through the successful Mars Phoenix mission in 2008, NASA and its partners have used similar entry, descent, and landing (EDL) system architectures with incremental improvements to deliver robotic payloads to the surface of Mars. This architecture is based on a rigid, blunt-body aeroshell (spherically-blunted, 70-degree half-angle cone), a supersonic disk-gap-band parachute, and a subsonic propulsive descent system used in sequence to decelerate the payload in the thin Martian atmosphere. Viking-based systems have delivered robotic payloads to the Martian surface from both orbit (Viking) and from direct entry (Mars Pathfinder, Mars Exploration Rovers, and Mars Phoenix). Table 1 summarizes previous Mars EDL systems developed by the United States that have successfully delivered robotic payloads, all of which were less than 0.6 metric tons ( $t$ ). The upcoming Mars Science Laboratory (MSL) mission (2011 launch) will have an entry system with the largest aeroshell ( $4.5 \mathrm{~m}$ diameter), largest supersonic parachute ( $21.5 \mathrm{~m}$ diameter), highest parachute deployment Mach number (2.1), and highest lift-to-drag ratio $(\mathrm{L} / \mathrm{D}=0.24)$ ever attempted at Mars in order to land less than 2 metric tons within 10 kilometers of the targeted landing site. Only minor improvements in landed mass and accuracy beyond MSL are believed to be possible using a similar entry system architecture. ${ }^{1}$

\section{A. Motivation and Objectives}

NASA's long-term Mars human exploration goals will require significant entry system improvements beyond MSL: at least an order of magnitude increase in payload mass (10s of metric tons), four orders of magnitude improvement in landing accuracy (meters), and the capability to land at higher altitudes to reach scientifically interesting sites. ${ }^{1}$ The ability of Viking-based entry systems to deliver payloads larger than MSL with higher precision is reaching a practical limit. This limit is largely due to physical constraints on parachute size and materials, deteriorating drag performance at increasingly higher deployment Mach numbers, and requirements that exceed the existing flight qualification envelope for both parachute size and deployment conditions. As a result, alternative EDL technologies are needed to enable delivery of the larger payloads needed for human (and advanced robotic) exploration of Mars. A recent study ${ }^{2}$ by NASA's EDL Systems Analysis (EDL-SA) team recommended that the Agency invest in new EDL technologies that include methods for improving entry system performance beyond that possible using Viking-derived methods: 
Table 1. Comparison of Mars Viking-Based EDL Systems ${ }^{1}$

\begin{tabular}{|c|c|c|c|c|c|}
\hline & Viking $1 \& 2$ & Pathfinder & MER A \& B & Phoenix & MSL \\
\hline \multicolumn{6}{|l|}{ Aeroshell Shape (to scale) } \\
\hline Aeroshell Diameter $(\mathrm{m})$ & 3.5 & 2.65 & 2.65 & 2.65 & 4.5 \\
\hline Entry Mass $(\mathrm{t})$ & 0.99 & 0.58 & 0.83 & 0.60 & 3.38 \\
\hline Ballistic Coefficient $\left(\mathrm{kg} / \mathrm{m}^{2}\right)$ & 64 & 63 & 94 & 70 & 140 \\
\hline Relative Entry Velocity $(\mathrm{km} / \mathrm{s})$ & 4.5 & 7.6 & 5.5 & 5.5 & 5.9 \\
\hline Hypersonic L/D & 0.18 & 0 & 0 & 0 & 0.24 \\
\hline Parachute Diameter $(\mathrm{m})$ & 16 & 12.5 & 14 & 11.7 & 21.5 \\
\hline Parachute Deployment Mach & 1.1 & 1.57 & 1.77 & 1.65 & 2.1 \\
\hline Total Landed Mass $(\mathrm{t})$ & 0.590 & 0.360 & 0.539 & 0.364 & 1.7 \\
\hline Lander or Rover Mass $(\mathrm{t})$ & 0.244 & 0.092 & 0.173 & 0.167 & 0.9 \\
\hline Landing Site Elevation (km) & -3.5 & -2.5 & $-1.9 /-1.4$ & -3.5 & -1.45 \\
\hline
\end{tabular}

- Deployable or inflatable aerodynamic decelerators that reduce ballistic coefficient $\left(\beta_{m}=m / C_{D} A_{r e f}\right)$ via larger drag area and higher drag at supersonic speeds compared to parachutes

- New rigid aeroshell shapes that improve lift-to-drag ratio (L/D)

- Propulsive deceleration during a larger portion of the EDL trajectory

Supersonic Retro-Propulsion (SRP) is included in the last group and involves initiating propulsive deceleration at supersonic Mach numbers by directing engine thrust into the oncoming freestream flow. The complexity of the interaction between the supersonic freestream and the retro-propulsion exhaust flow is illustrated notionally in Figure 1 for a single jet. For the case shown, the supersonic jet plume terminates in a shock behind the main bow shock, with a free stagnation point in between. The location and existence of these features are largely a function of the ratio of jet total pressure to freestream total pressure. The total effective drag coefficient using a system such as that shown in Figure 1 is derived from the aeroshell's aerodynamic drag $\left(C_{D}=D / q_{\infty} A_{r e f}\right)$ and the propulsive drag provided by the engines (thrust coefficient, $\mathrm{C}_{\mathrm{T}}=\mathrm{T} / \mathrm{q}_{\infty} \mathrm{A}_{\mathrm{ref}}$ ):

$$
\mathrm{C}_{\mathrm{D}, \text { Total }}=\mathrm{C}_{\mathrm{D}}+\mathrm{C}_{\mathrm{T}}
$$

Depending on the entry system mass and deceleration requirements, especially for human-scale payloads, the propulsive drag term in the above equation may be the dominant contributor to the total effective drag. The EDLSA team considered SRP systems that delivered thrust coefficients above 10, which far exceed the typical bluntbody drag coefficient of around 1.5. Previous wind tunnel studies ${ }^{3}$ suggest that the use of retro-rockets can at best maintain the native aerodynamic drag, and at worst reduce the aerodynamic drag to nearly zero, depending on the retro-rocket configuration and thrust coefficient. In the case where aerodynamic drag is eliminated or is small relative to the propulsive drag term, the total entry vehicle drag is derived from the engine thrust alone. These trends are illustrated from experimental data in Figure 2. These studies also suggest the latter case (dominant propulsive drag) to be more relevant for flight systems of the scale required for human Mars exploration. 


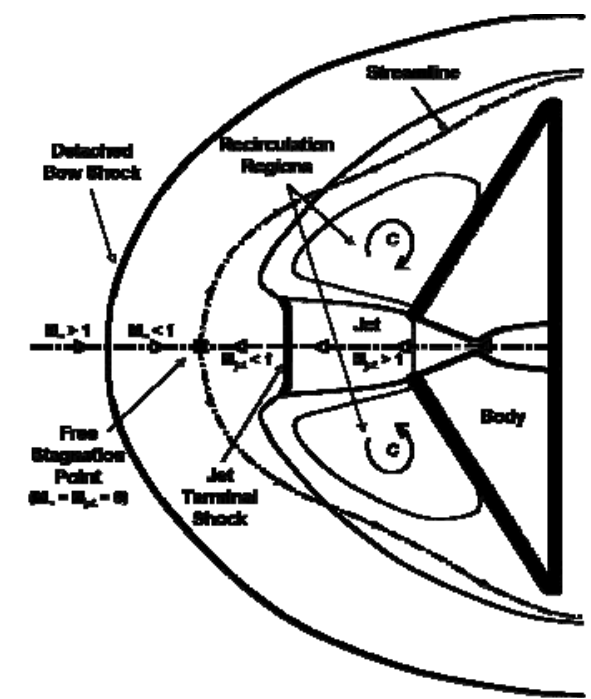

Figure 1. Interaction Between Supersonic Freestream and Exhaust from a Single Nozzle ${ }^{4}$

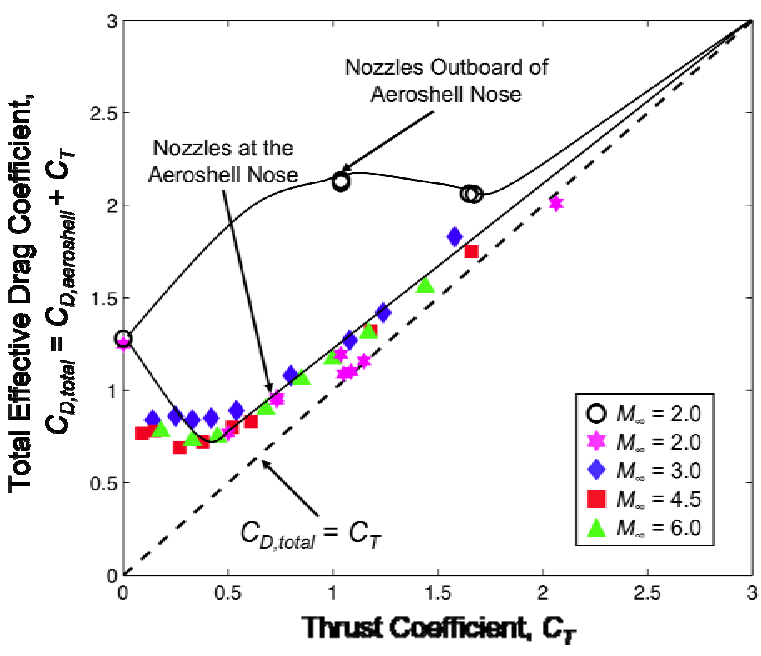

Figure 2. Experimental Data for Total Effective Drag as a Function of Thrust Coefficient ${ }^{4}$

Figure 3 illustrates notional EDL system architectures that were studied by the EDL-SA group. ${ }^{2}$ Each architecture contains a sequence of events and methods for delivering a human-scale payload to the surface of Mars using technologies that have never been flown or demonstrated at the required scale. Architecture 1 was adopted from previous studies as part of the Mars Design Reference Architecture 5.0 (DRA5). ${ }^{5}$ This architecture consists of a rigid, slender aeroshell used for aerocapture and hypersonic deceleration, followed by an SRP phase ending at terminal descent. Four of the remaining eight architectures (2, 3, 4, and 9) also include a propulsive deceleration phase in the supersonic Mach number regime. Architecture 1 was ranked highest by the EDL-SA team, mostly due to high scores for safety and performance. The EDL-SA team completed a parametric SRP sizing and performance analysis to estimate mass fraction and thrust requirements for a $40 \mathrm{t}$ payload. The propulsion system baseline for the EDL-SA study was derived from DRA5 and adjusted to satisfy mission objectives:

- Six liquid oxygen, liquid methane $\left(\mathrm{LO}_{2} / \mathrm{LCH}_{4}\right)$ engines, each delivering a maximum thrust of $300 \mathrm{kN}$

- Engines capable of throttling down to $20 \%$ of full thrust

- Two propellant tanks each for the $\mathrm{LO}_{2}\left(8.2 \mathrm{~m}^{3}\right.$ per tank $)$ and $\mathrm{LCH}_{4}\left(6.1 \mathrm{~m}^{3}\right.$ per tank $)$

Given the demonstrated benefits of SRP in the EDL-SA architectures, the study recommended further investment by NASA to begin the maturation of SRP into a viable decelerator technology. 


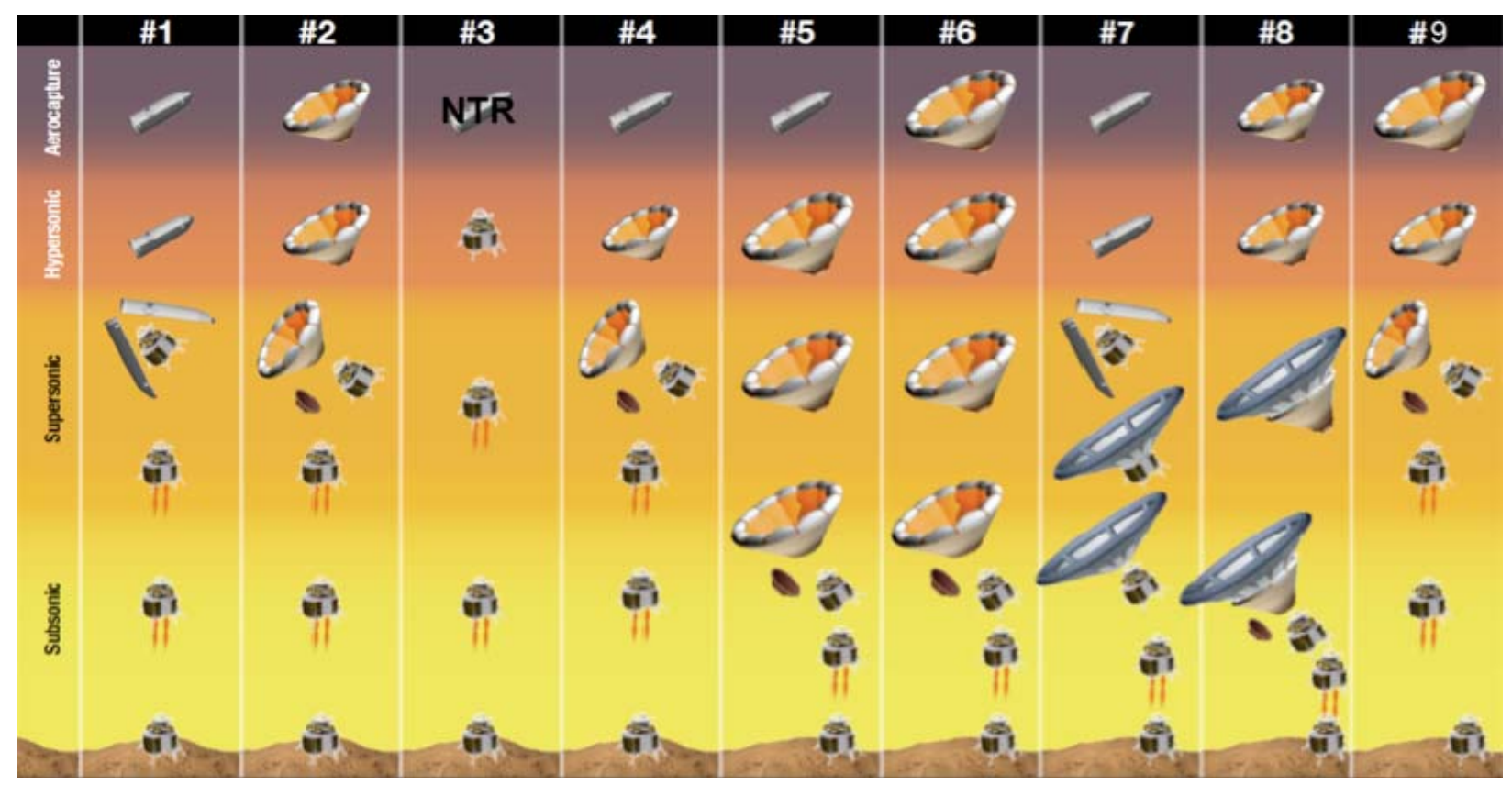

Figure 3. Aerocapture/EDL Architectures for Human-Scale Mars Exploration ${ }^{2}$

The responsibility for forming a team focused on human-scale SRP development was given to NASA's Exploration Technology Development Program (ETDP) EDL Project. Given the desire to advance the technical maturity of SRP, one of the team's first tasks was to construct a SRP technology development roadmap with several goals:

- Identify the major component SRP technologies in need of maturation

- Assess the current technical maturity of SRP using NASA guidelines

- Determine experimental and analytical achievements that are needed to mature SRP into a viable decelerator technology

- Specify metrics by which to measure the technical advancement of SRP

- Develop an technology maturation schedule

This paper summarizes the work performed to date by the ETDP team towards achieving the above objectives. The products shown here represent a starting point to foster further discussion on how best to develop SRP into a decelerator technology that NASA can use to significantly improve landed mass capabilities on future Mars missions. 


\section{B. Historical Background}

The concept of supersonic retro-propulsion for Mars EDL predates the Viking missions. A focused technology development effort in the 1960s and 1970s developed SRP to nearly the level of maturity the concept has today. The eventual selection of a supersonic parachute system and subsonic propulsive terminal descent phase for the Viking landers ended much of the research efforts to develop SRP. ${ }^{4}$ Only recently has interest in SRP as a supersonic decelerator resurfaced. Efforts to define requirements and architectures for advanced robotic and human Mars exploration ${ }^{1,2,5}$ have identified SRP as a potentially enabling EDL technology, and development efforts within EDL-SA and ETDP teams have resumed from where original investigations left off more than 30 years ago.

A substantial number of wind tunnel tests were completed in the 1960s and early 1970s using small-scale models of blunt-body aeroshells with retropropulsion nozzles. ${ }^{4}$ The intent of these tests was to understand drag effects potentially advantageous to EDL. While the test conditions and vehicle configurations were limited, these test series demonstrated that the SRP aerodynamic/propulsive interaction significantly alters the aerodynamic characteristics of the vehicle and fundamentally differs from subsonic terminal propulsion. Retropropulsion configuration and thrust coefficient were found to drive the degree of change in the vehicle's aerodynamic characteristics. Simple analytical models were developed from experimental trends, and these models were then used to size and scale SRP systems for prototypical Mars landers. ${ }^{4}$

Current objectives of using SRP for advanced robotic and human missions differ in physical scale from those when the concept of SRP was originally formulated. However, extensible trends in static aerodynamics as a function of retro-propulsion configuration, freestream conditions, and thrust have been established from this historical work. These trends have been integrated into recent studies, ${ }^{2,6,7}$ and bounds on SRP initiating and operating conditions, system sizing, and performance have been determined. These studies have demonstrated the potential of SRP technology to increase landed mass at Mars and motivated efforts to increase the fidelity of SRP models through the construction of aerodynamic databases with computational fluid dynamics (CFD) tools.

The significant time gap in SRP development resulted in little published work on CFD simulation of SRP flowfields. Much of the existing work is focused on reducing the overall drag of the vehicle or the severity of the aerothermal environment, rather than augmenting the total effective drag of the vehicle through retro-propulsion. ${ }^{4}$ However, the similarities between the aerodynamic/propulsive interactions across existing work and SRP flowfields have been useful in extending computational approaches to the SRP problem. CFD analyses that accurately capture SRP aerodynamic/propulsive interactions exist under a very limited range of conditions, and the difficulty in generating a relevant aerodynamic database for systems analysis remains a challenge to maturing SRP technology.

The current maturity of SRP aerodynamics is limited by the existing experimental database. Historical work is limited in terms of retro-propulsion configurations, flight-relevant freestream and thrust conditions, and uncertainty in collected data. ${ }^{4}$ Additionally, no historical information has been found on the start-up of a high-thrust propulsion system directly opposing supersonic flow, controllability of vehicles utilizing SRP, sub-scale flight testing, or the integration of an SRP system into an EDL architecture. Despite these limitations, the current state-of-the-art for SRP technology includes:

- Systems analysis of integrated vehicles utilizing SRP with experimentally-derived models for aerodynamic/propulsive interactions

- Preliminary CFD solutions of SRP flowfields anchored to existing experimental data

- Wind tunnel testing at relevant thrust conditions for CFD simulation and model development

The identification of SRP as a technology with the potential to improve EDL system performance beyond that achievable with Viking-heritage systems has been strongly dependent upon knowledge gained from historical SRP development efforts. To be considered as a viable decelerator technology option on future flight projects, SRP requires a development roadmap that moves beyond reliance on historical efforts. 


\section{Technology Development Roadmap}

The SRP development roadmap presented here is framed around the advancement of all necessary component technologies and an integrated system using NASA guidelines for measuring technology maturation. NASA's Technology Readiness Level ${ }^{8}$ (TRL) scale defines progressive levels of technical maturation, from observation of basic principles (TRL 1) through successful application on a spaceflight mission (TRL 9). Table 2 shows the TRL definitions and descriptions (1 through 6) considered by NASA to be critical for technology advancement. The Agency uses TRLs as one method of determining the readiness of a technology for its intended purpose and guiding decisions about funding and risk assessment. In order to be considered sufficiently mature for incorporation onto a NASA flight project, a technology often must first achieve TRL 6, "System/subsystem model or prototype demonstration in a relevant environment (ground or space)," by the project Preliminary Design Review. Achieving TRL 6 may involve the successful testing of a sub-scale prototype system in Earth's atmosphere as a means to validate and qualify the system for use on a precursor mission at Mars. If SRP is to be used for human exploration missions, robotic precursors at Mars will undoubtedly be required to demonstrate successful operation in that environment. In fact, Mars demonstration at a sufficient scale may be necessary for SRP to achieve TRL 6 for human missions. At that point, a flight project may take over the focused development and qualification of the technology for its specific purpose through space operations (TRL 9). The roadmap discussed here is formulated for SRP to achieve TRL 6 for adoption on a robotic-scale (similar to MSL) flight project at Mars. Significant additional development activities beyond what are shown here would be needed to advance SRP for human-scale use.

Table 2. NASA Technology Readiness Levels ${ }^{8}$ (1 through 6)

\begin{tabular}{|c|c|c|}
\hline TRL & Definition & Description \\
\hline 1 & $\begin{array}{l}\text { Basic principles } \\
\text { observed and reported }\end{array}$ & $\begin{array}{l}\text { This is the lowest "level" of technology maturation. At this level, scientific research } \\
\text { begins to be translated into applied research and development. }\end{array}$ \\
\hline 2 & $\begin{array}{l}\text { Technology concept } \\
\text { and/or application } \\
\text { formulated }\end{array}$ & $\begin{array}{l}\text { Once basic physical principles are observed, then at the next level of maturation, } \\
\text { practical applications of those characteristics can be "invented" or identified. At } \\
\text { this level, the application is still speculative: there is not experimental proof or } \\
\text { detailed analysis to support the conjecture. }\end{array}$ \\
\hline 3 & $\begin{array}{l}\text { Analytical and } \\
\text { experimental critical } \\
\text { function and/or } \\
\text { characteristic proof-of- } \\
\text { concept }\end{array}$ & $\begin{array}{l}\text { At this step in the maturation process, active research and development (R\&D) is } \\
\text { initiated. This must include both analytical studies to set the technology into an } \\
\text { appropriate context and laboratory-based studies to physically validate that the } \\
\text { analytical predictions are correct. These studies and experiments should constitute } \\
\text { "proof-of-concept" validation of the applications/concepts formulated at TRL } 2 \text {. }\end{array}$ \\
\hline 4 & $\begin{array}{l}\text { Component and/or } \\
\text { breadboard validation in } \\
\text { laboratory environment }\end{array}$ & $\begin{array}{l}\text { Following successful "proof-of-concept" work, basic technological elements must be } \\
\text { integrated to establish that the "pieces" will work together to achieve concept- } \\
\text { enabling levels of performance for a component and/or breadboard. This validation } \\
\text { must be devised to support the concept that was formulated earlier, and should also } \\
\text { be consistent with the requirements of potential system applications. The validation } \\
\text { is relatively "low-fidelity" compared to the eventual system: it could be composed of } \\
\text { ad hoc discrete components in a laboratory. }\end{array}$ \\
\hline 5 & $\begin{array}{l}\text { Component and/or } \\
\text { breadboard validation in } \\
\text { relevant environment }\end{array}$ & $\begin{array}{l}\text { At this TRL, the fidelity of the component and/or breadboard being tested has to } \\
\text { increase significantly. The basic technological elements must be integrated with } \\
\text { reasonably realistic supporting elements so that the total applications (component- } \\
\text { level, sub-system level, or system-level) can be tested in a "simulated" or somewhat } \\
\text { realistic environment. }\end{array}$ \\
\hline 6 & $\begin{array}{l}\text { System/subsystem } \\
\text { model or prototype } \\
\text { demonstration in a } \\
\text { relevant environment } \\
\text { (ground or space) }\end{array}$ & $\begin{array}{l}\text { At TRL 6, a representative model or prototype system or system would be tested in a } \\
\text { relevant environment. At this level, if the only "relevant environment" is the } \\
\text { environment of space, then the model/prototype must be demonstrated in space. Of } \\
\text { course, the demonstration should be successful to represent a true TRL } 6 \text {. Not all } \\
\text { technologies will undergo a TRL } 6 \text { demonstration: at this point the maturation step is } \\
\text { driven more by assuring management confidence than by R\&D requirements. }\end{array}$ \\
\hline
\end{tabular}




\section{A. Component Technologies}

The use of large engines directed into a supersonic flow opens up numerous technical challenges that have mostly been unaddressed at NASA or elsewhere. Advancement of a number of key technologies is considered to be critical to the maturation of SRP into a method for supersonic deceleration of large-scale entry vehicles. Interactions between the engine plumes, the freestream flow, and the entry vehicle present a number of challenges that will affect the technological advancement and practical application of SRP. These technical challenges, for the purpose of developing the roadmap, have been divided amongst the major components of an SRP system. Table 3 summarizes some of the major technical challenges foreseen in the areas of propulsion, aerodynamics/aerothermodynamics, guidance, navigation, and control (GN\&C), systems engineering and analysis, and ground/flight testing. These challenges will need to be addressed and overcome for SRP to achieve TRL 6. Additional challenges are likely to arise as the maturation of SRP continues. The following section describes in more detail the approaches to address these challenges in each of the major technical areas listed in Table 3 along with the necessary advancements to achieve TRL 6.

As with any EDL technology, analytical models and tools will be an important aspect of the technical maturation of SRP. These models will be required to predict, among other things, engine performance, aerodynamic/propulsive interactions, aerothermal effects due to plume impingement, structural and thermal loads, and simulate entry vehicle configuration and flight mechanics. Many of these models will be required to analytically assess EDL system performance through three and six degrees of freedom (3-DOF/6-DOF) entry trajectory simulations. The fidelity of the models that feed into the trajectory analyses must advance in TRL concurrently with the SRP hardware and must be validated using ground test data when available. ETDP has already started the process of identifying critical modeling needs for large-scale Mars EDL systems.

The advancement of analysis methods will require several ground test campaigns in facilities that can achieve environments relevant to conditions expected at Mars. For example, in the case of wind tunnel aerodynamics testing, relevant environments may mean matching the appropriate combinations of Mach number, thrust coefficient, and angle-of-attack. The responsibility for bridging the gap between ground facility limitations and fullscale conditions, such as entry vehicle scale, will fall onto validated CFD tools. One of the primary goals for any of the planned tests, especially in the areas of aerodynamics and engine performance, will be to provide a database that can be used to validate analytical models for application to full-scale Mars conditions. One area that will require significant effort, specifically for SRP, will be the CFD prediction of aerodynamic and propulsive forces and moments that are imparted onto the entry vehicle. These forces and moments will affect both the entry system performance (drag) and stability/controllability requirements. Some of the needed improvements, such as turbulence modeling, may directly affect SRP. Current efforts are ongoing ${ }^{9,10}$ to gage the current state of existing CFD codes applied to SRP and identify future development needs.

\section{B. Technology Readiness Level Achievement Criteria}

As an integrated set of component technologies, SRP has been assessed to have more or less achieved TRL 2, "Technology concept and/or application formulated." This evaluation is based on work identifying SRP as a decelerator technology for Mars EDL, but with little data to support that SRP can be successfully developed and implemented for such a purpose at the scale desired. The authors are not aware of any engine tests where startup and steady operation have been demonstrated against a supersonic freestream. Most of the past work related to SRP has focused on sub-scale wind tunnel testing ${ }^{4}$ aimed at understanding the aerodynamic trends and benefits when jets are directed into the freestream flow. CFD studies ${ }^{9,10}$ have demonstrated promising results when compared to SRP wind tunnel data, but substantial work remains to fully validate computational methods. Recent architecture studies that include SRP, such as the EDL-SA investigation ${ }^{2}$, have used low-fidelity models designed to meet requirements rather than models based on proven performance data from analysis or experiment. The following sections describe in more detail the technical advancements needed in the various components and the methods to be used to advance from the current state to TRL 6. TRLs have been and will be achieved through a combination of analysis, ground tests, and/or flight experiments. Some of the SRP components are ahead of others in technical maturity, and some will require more investment than others to advance through the remaining levels. Those TRL achievements that have already occurred are indicated as such in the following discussion. 
Table 3. Major SRP Technical Challenges

\begin{tabular}{|c|c|c|}
\hline \hline Technology Area & Major Technical Challenges \\
\hline Propulsion & $\begin{array}{c}\text { Developing large engines capable of throttling with sufficient thrust for } \\
\text { human-scale payloads (100s of kN) }\end{array}$ \\
\hline Aerodynamics/ & - $\begin{array}{c}\text { Demonstrating reliable engine startup and throttling against supersonic flow } \\
\text { Aerothermodynamics }\end{array}$ & $\begin{array}{c}\text { and moments) and aedicthermodynamics (surface heating) } \\
\text { Developing and validating CFD models and tools needed to build full-scale } \\
\text { aerodynamics and aerothermodynamics databases }\end{array}$ \\
\hline GN\&C & $\begin{array}{c}\text { Developing algorithms and systems to dynamically control and stabilize the } \\
\text { entry vehicle in the presence of complex fluid dynamic interactions }\end{array}$ \\
\hline Integrated Systems & $\begin{array}{c}\text { Configuring the SRP engines on candidate entry vehicle geometries to } \\
\text { satisfy the required system performance }\end{array}$ \\
\hline Engineering and Analysis & $\begin{array}{c}\text { Packaging the propulsion system within the volume and mass constraints of } \\
\text { the EDL system }\end{array}$ \\
\hline Verifying and validating the integrated SRP system performance models \\
(propulsion, flight mechanics, aerodynamics, aerothermodynamics, \\
GN\&C, thermal, structural)
\end{tabular}

\section{Propulsion}

As shown in Table 3, the major technical challenges for the propulsion subsystem are developing large throttleable $\mathrm{LO}_{2} / \mathrm{LCH}_{4}$ engines with sufficient thrust for human-scale payloads, demonstrating reliable engine startup, and throttling against a supersonic flow. Since the testing of large-scale engines and the counterflow supersonic environment are (in general) mutually exclusive, these two challenges must be addressed separately. Consequently, the large engine development effort follows the classic approach of scaling up existing engines, utilizing existing and modified hardware, and then building full-scale prototype engines for ground testing. The reverse supersonic flow startup and throttling effort follows a largely separate path, relying on CFD, scaled wind tunnel testing, and scaled Earth-based flight testing. The efforts are complementary and are worked in parallel, each providing insight and feedback for the other.

As previously noted, the notional vehicle and propulsion system for a human-scale mission was defined in the EDL-SA study. ${ }^{2}$ The liquid oxygen/liquid methane propellant combination was chosen since it is generally considered both space-storable and in-situ resource utilization (ISRU) compatible. The ability to produce return mission propellants at Mars significantly reduces both launch mass at Earth and landed mass at Mars. Given an initial vehicle combined mass of $62 \mathrm{t}$ and a 3 Earth g's initial deceleration, $1.8 \mathrm{MN}$ ( $400 \mathrm{klb}_{\mathrm{f}}$ ) of initial thrust is required. The final system thrust is throttle-able down to $\sim 10 \%$ at touchdown. Most large pump-fed engines have a lower limit of $\sim 50 \%$ thrust due to the combined effects of injector dynamics, pump and turbine design, engine cooling, and performance drop-off at low throttle levels. A recent demonstration of a modified version of the RL-10 $\mathrm{LO}_{2} / \mathrm{LH}_{2}$ engine achieved $13 \%$ throttling, which suggests the potential for at least one well-characterized engine. Pressure-fed engines are more amenable to wide throttle ranges but are impractical for the large thrust levels needed for a Mars lander. Throttle considerations, along with a desire from the vehicle control team to have engines in multiples of three, led to a notional design of 6 engines ( $300 \mathrm{kN}$ each) for the EDL-SA study. Such a cluster could 
have half of the engines shut down at $40-50 \%$ throttle, with the balance throttled up to $100 \%$, to maintain the descent rate. The remaining 3 engines would throttle down to $\sim 20-30 \%$ for landing, a reasonable goal for throttle range with many years left to develop such an engine. With half of the engines operating at low throttle, the desired $\sim 10 \%$ total thrust at shutdown is thus achieved.

The state of the art for $\mathrm{LO}_{2} / \mathrm{LCH}_{4}$ propulsion has been driven primarily by recent development efforts funded through ETDP. These efforts are all geared toward relatively low thrust and low $\Delta \mathrm{V}$ missions, e.g. a Lunar Ascent vehicle. The total technology effort is ongoing at 6 NASA centers and a dozen contractors across 30 or 40 separate technology development programs. Overall, the TRL could be considered 5-6 for reaction control system (RCS) and small main engines, and 2-3 for large, throttle-able main engines. Some of the significant ETDP engine development efforts include a prototype $22 \mathrm{kN}\left(5 \mathrm{klb}_{\mathrm{f}}\right)$ fixed thrust ascent engine, a $176 \mathrm{kN}\left(40 \mathrm{klb}_{\mathrm{f}}\right)$ breadboard injector with heat sink chamber, a $44 \mathrm{kN}\left(10 \mathrm{klb}_{\mathrm{f}}\right)$ workhorse engine, and several $444 \mathrm{~N}\left(100 \mathrm{lb}_{\mathrm{f}}\right)$ RCS thrusters delivered. In addition to the ETDP work, numerous studies have been performed on $\mathrm{LO}_{2} / \mathrm{LCH}_{4}$ engines, from $44 \mathrm{kN}$ to $900 \mathrm{kN}$. In all cases, the goal of a high specific impulse engine will have, by necessity, a large expansion ratio nozzle that will complicate vehicle structural and dynamic interactions with the external flowfield.

To advance the TRL for Mars-appropriate SRP, it will be necessary to perform conceptual design and analysis trades (e. g. conventional nozzles, aerospike) and to prepare candidate designs with adequate detail to define specific test hardware, levels, and durations. TRL 4 is achieved with a full-scale development unit engine using a short sea level nozzle with demonstration of startup, minimal throttling, and shutdown. As an example, Pratt-Whitney has studied and performed turbopump testing for a $266 \mathrm{kN}\left(60 \mathrm{klb}_{\mathrm{f}}\right)$ derivative of their RL10 engine, adapted for $\mathrm{LCH}_{4}$ and renamed the PWR-35M development engine. TRL 5 might then be achieved with altitude testing of a similar or second generation version. Numerous other engine studies are available in the AIAA and JANNAF databases, although relatively little hardware has been built or tested. One promising concept for reducing engine height is an aerospike (or plugless nozzle) solution, although throttling would likely be a challenge with a single large engine. The aerospike concept is generally chosen for its inherently altitude-compensating nozzle-less external flowfield, but the elimination of the large nozzle makes it an attractive alternative for a Mars lander mission, albeit with a likely mass penalty of $10-15 \%$.

Demonstrating reliable engine startup and throttling against a supersonic flow is the second major challenge requiring significant development effort to achieve TRL 6 . This requirement will be addressed through a combination of analysis, wind tunnel testing, and flight testing at Earth. Engine startup in a reverse flowfield during Mars entry has at least three major considerations: engine static pressure at startup, the subsequent dynamic pressure/flow environment interacting with the nozzle flow streams, and nozzle stiffness. At Mach 3, the startup pressure in the chamber was calculated as $5.2 \mathrm{kPa}(0.75 \mathrm{psia})$. This modest pressure is well within the state-of-theart, since both sea level and vacuum starts are common operations. More significant challenges are the dynamic interaction between a large nozzle and the unsteady flow stream around the vehicle at startup, the subsequent dynamic response of the flow stream to mass flow introduced behind the bow shock, and having sufficient nozzle stiffness in the opposing flow. The size of the nozzles (relative to the vehicle) will be much larger than has ever been tested in wind tunnels; placement inside a region with subsonic could alleviate the negative effects of shock interactions during startup. Similarly, the mass flow directed into the oncoming flow will be much larger. Another layer of complexity is introduced with multiple nozzles interacting both with each other and the environment. Achieving TRL 3 will require a Mars-specific CFD analysis and correlation with wind tunnel test data, generated with a simple cold gas propulsion system (includes both startup and dynamic response). Advancing to TRL 4 will require a more complex and flight-like wind tunnel test series with a hot-gas propulsion system and another round of analytical model improvement and correlation. TRL 5 will require the above, plus throttling and off-nominal conditions in a simulated Mars environment in a wind tunnel. Finally, Earth-based flight tests will require a propulsion system capable of startup and throttling in relevant conditions to achieve TRL 6 .

A secondary challenge related to the propulsion system is cryogenic storage of propellants for the lander vehicle. A combination of lightweight liner-less composite overwrapped pressure vessel (COPV), along with suitable insulation and thermal management will be required to meet the mission timeline. Testing and analysis at NASA Johnson Space Center and within ETDP suggests that propellant boil-off losses can be very small, even without active cooling. The key technology development is the liner-less COPV and a long-term thermal storage test would be required to verify performance in a flight-like configuration. 


\section{Aerodynamics \& Aerothermodynamics}

The diversity of the flow physics created by the interaction of retro-propulsion exhaust plumes and a supersonic external flow poses difficult challenges to entry vehicle aerodynamics (forces and moments) and aerothermodynamics (surface heating) predictions. The SRP system will be asked to enhance entry vehicle drag and maintain entry vehicle stability and control in the presence of these interactions, which will likely be unsteady during startup and full-thrust operations. Consequently, knowledge of the aerodynamic/propulsive interactions will be critical for entry system performance predictions. Entry trajectory simulations (3- and 6-DOF) will rely heavily on aerodynamic characteristics derived from validated CFD methods and tools. Also, thermal protection system (TPS) design will require CFD input to estimate the effects of plume impingement heating and exhaust flow contamination. While all prior Mars EDL work focused on flying entry vehicles of a well known shape, the presence of retro-rockets changes the effective shape of the vehicle that the flow encounters, which in turn complicates prediction of aerodynamics and aeroheating. This can result in a more complex relationship between the aerodynamic environment, the freestream conditions, the entry vehicle's angle-of-attack, and the engine thrust. Furthering the predictive capabilities of SRP aerodynamics and aerothermodynamics will require a combination of wind tunnel testing and CFD validated with test data in an effort to understand these interactions.

The knowledge and prediction capability of SRP aerodynamics and aerothermodynamics is currently estimated to be at TRL 2 based on past wind tunnel testing of various geometries and jet configurations, ${ }^{4}$ and recent assessments of CFD capabilities. ${ }^{9,10}$ The achievement of TRL 1 was based on previous wind tunnel tests that demonstrated SRP's basic physics and aerodynamic trends for single and multiple jets. ${ }^{4}$ Advancement through TRL 3 is accomplished with further wind tunnel testing of generic configurations (e. g. model geometry, number and arrangement of jets) designed specifically to validate CFD methods. ${ }^{9}$ Confidence in CFD must be established in order to support 3- and 6-DOF trajectory simulations that require entry vehicle aerodynamic databases. The databases provide entry vehicle force and moment coefficients as a function of numerous parameters, including Mach number, angle-of-attack, and thrust coefficient. A wind tunnel test is planned for this year in the NASA Langley Research Center Unitary Plan Wind Tunnel specifically to provide additional data for CFD assessment and identification of modeling deficiencies. ${ }^{9}$ Additional wind tunnel testing will follow with more configurations and conditions. TRL 3 is achieved when acceptable CFD accuracy of aerodynamics and aerothermodynamics is demonstrated in comparison to wind tunnel data. Once confidence in CFD capabilities is established, TRL 3 activities will continue with the development of first-order CFD-based Mars vehicle databases and wind tunnel testing on more representative Mars configurations.

Advancement through TRL 4, 5 and 6 will be achieved with demonstration of improved fidelity of analysis of increasingly complex physics. Continuing convergence of CFD predictions and ground test data in terms of aerodynamics and aeroheating is shared among the readiness levels 4, 5 and 6. Comparison between the numerical predictions and data allows to assess the fidelity of aerodynamic and aeroheating predictions for Mars applications. These predictions for the actual flight environment are needed to construct flight simulations and to accurately determine requirements on the propulsion, control, and thermal protection systems. Accurate modeling of the unsteady effects, such as engine start and throttling, as well as the unsteady interaction flowfield at a constant angle of attack and with a pitching motion is required. In order to support this aspect of CFD and engineering tool development, a series of wind tunnel tests have been proposed. Because the program includes flight tests in Earth's atmosphere, analysis of expected interactions and post-flight analysis are part of the TRL 6 achievement. By this time the predictive tools and their uncertainty in the relevant environment should be well characterized.

Various CFD codes have been exercised for an initial set of SRP test cases from available historical wind tunnel data sets. ${ }^{9,10}$ The test cases included single nozzle and 3-nozzle (air exhaust) configurations on blunt body wind tunnel models. A limited set of conclusions regarding CFD capabilities for SRP can be made based on the test cases run to date. Further assessments and validation exercises will be possible once more detailed sets of wind tunnel data become available that address current dataset limitations, especially in the area of data uncertainties and flowfield unsteadiness. The agreement between CFD and measurements of surface pressure vary with freestream Mach number and thrust coefficient. Surface pressure coefficients as predicted by CFD match well with the single nozzle test case ${ }^{3}$ for a thrust coefficient of 7 (Figure 4). 


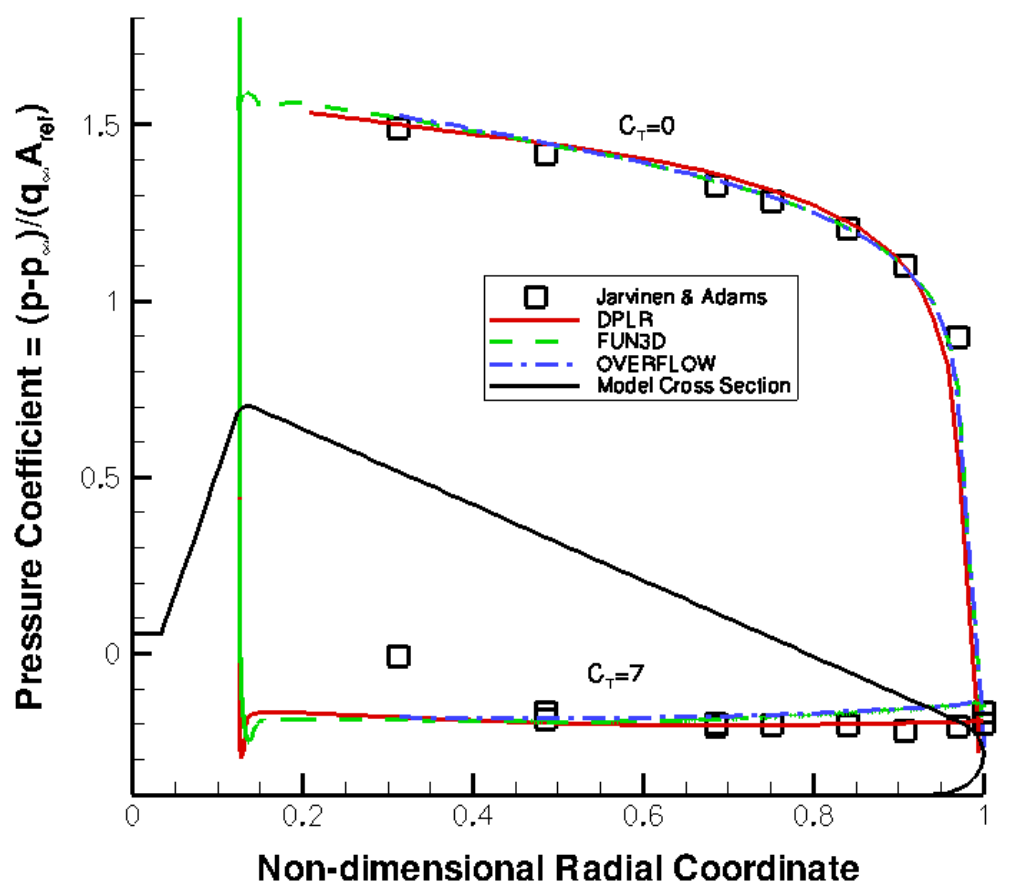

Figure 4. Comparison of CFD and Wind Tunnel Surface Pressure Coefficient $\left(C_{T}=0\right.$ and Single SRP Nozzle with $\left.\mathrm{C}_{\mathrm{T}}=7\right)^{9}$

Aerodynamic/propulsive interactions have previously received attention in several flight projects. The negative effects of attitude control jets on aerodynamics were reported for the Space Shuttle. ${ }^{11}$ More recently, the effects of RCS during entry have been predicted for Mars Phoenix, ${ }^{12}$ MSL, ${ }^{13}$ and Orion Crew Exploration Vehicle. ${ }^{14}$ For these cases, induced aeroheating and the interaction with the control system authority were based on wind tunnel testing and CFD predictions. Experimental efforts are often complicated by the need to determine scaling and simulation parameters, which for jets may involve external flow, nozzle-local flow, gas compositions, the turbulent transition scales in various regions of the flowfield, as well as the interaction with the model support. Because of these difficulties, wind tunnel simulation is frequently approached and regarded more as a CFD validation effort. Scaling parameters generally reflect objectives of the test, but the order of effects may not be known a priori. Because of these challenges, the numerical methods are required for analysis of the flight vehicle. In the case of the above listed examples CFD analysis was done using the available methods and was found to have difficulty with grid density, appropriate turbulence modeling, and unsteadiness. These challenges appear to be common to SRP, and are reflected in the outlook on the technology maturation.

\section{Guidance, Navigation, and Control}

The current vision is that the SRP engines will be used not only during supersonic descent, but also through transonic and subsonic conditions to touchdown. The GN\&C requirements and capabilities for SRP are immature at this time due to NASA's lack of experience with this type of flight concept. The flowfield complexity and dynamic interactions between the exhaust plumes, freestream, and entry vehicle will challenge GN\&C algorithms and systems designed for stability and control. Historically, experience gained from powered lunar landings during the Apollo program demonstrated the importance of factoring the human design aspects early into the GN\&C tradespace. Considerations such as viewing, terrain clearance, and lighting will drive trajectory design considerations and assist selection of GN\&C sensors and avionics. Tolerance to stochastic powered flight transients and accommodating precision landing and contingency flight (abort-to-orbit, abort-to-landing, target re-designation, and hover-hop) requirements will drive propulsion system trades (engine throttle rate and range), fuel tank loading 
margins, and control system RCS/gimbal-rate selection and sizing. Therefore, a comprehensive approach to develop and understand the physics and interactions between the SRP system will be necessary to properly anchor the analytical and numerical approximations used to formulate the GN\&C.

The TRL 1 achievement criteria for GN\&C are to successfully implement SRP into 3-DOF trajectory simulations to show the expected cost/benefit. This task has been completed by the EDL-SA task, ${ }^{2}$ Georgia Tech, ${ }^{6,7}$ and others showing the need for SRP at Mars. Achievement criteria for TRL 2 place more emphasis on the utilization and understanding of different SRP flight concepts, including but not limited to: gimbaled engines, differential throttling, and RCS control. The reasons for developing multiple concepts early on are that the SRP GN\&C system will need to leverage various options available to accommodate deviations from the nominal design.

As SRP knowledge improves, so will the driving requirements for GN\&C system selection and operation, such that by TRL 3, the GN\&C is better suited to handle the expected flight environments. The achievement criteria for TRL 3 are to understand the various interactions of avionics and sensors with the GN\&C system in 3- and 6-DOF simulation environments. A selection of avionics systems may themselves affect the final trajectory shaping due to limitations in sensor scanning operation. Target re-designation, hazard detection and avoidance, crew interaction, and manual control capability requirements will also help to define the GN\&C avionics support sub-systems.

The achievement criteria for TRL 4 require the GN\&C to react in real-time to perturbations in a 6-DOF simulation environment such that a robust system can be tuned for a variety of flight conditions. The challenge expected here is that aerodynamic interactions during the SRP phase will be rapid and chaotic, possibly requiring the GN\&C system to react more quickly than systems designed for previous NASA missions. This learning curve will need to be overcome by extensive validation and verification of the analytic and numerical models used to determine the SRP perturbations.

The achievement criteria for TRL 5 and 6 focus largely on the validation and verification of GN\&C models used in planning and execution of Earth atmosphere flight tests, as described below. The V\&V of the GN\&C models will utilize a single and/or combined process of testing, analyses, and inspection of data supplied by wind tunnels, material testing, hardware and software testing of subscale and scale flight models and demonstrations to ensure the system performs adequately for a human rated system throughout all expected flight conditions. The initial development phase for GN\&C models will insure that a set of requirements are developed that insure the correct system is built that is achievable and verifiable. The flight test progression proposed here ensures that an integrated closed-loop GN\&C system is built correctly to the requirement specifications and provides a safe, stable, and fuel optimal response to entry vehicle perturbations caused by SRP aerodynamic/propulsive interactions. Acceptable margins will need to be defined and understood relative to the flight test data correlation. An adequate validation and verification program will enable the SRP GN\&C to be capable of designing to the conditions that will constitute the SRP flight concepts used by various missions.

GN\&C analyses will initially be used to show theoretical compliance to requirements and establish that the technical/program risk versus benefit trade provides a cost and schedule effective solution. Analyses by similarity will also be used when it can be shown that an article is similar in design, manufacture, and use to an equivalent or more stringent previously qualified GN\&C hardware or software component. Similarity analyses must be supplemented if the desired component is integrated into a larger assembly of divergent character than the original qualified use (for example, a powered lunar guidance algorithm applied for atmospheric Mars entry). The final product will be an integrated GN\&C system qualified to meet all mission, performance, and life-cycle human rated SRP program requirements.

\section{Integrated Systems Engineering \& Analysis}

The Integrated Systems Engineering and Analysis technology area is focused on the definition of requirements and demonstration of acceptable SRP performance at the vehicle level. As given in Table 3, the major technical challenges for the integration of a flight system utilizing SRP are ensuring that it can be packaged within the volume and mass constraints of the EDL system, and performing verification and validation activities to ensure performance of the integrated SRP system. These activities include a combination of ground and flight tests, augmented with analytical modeling using validated tools. The TRL achievement criteria for the integrated system are based upon a progression of increasingly higher-fidelity and integrated sub-system demonstrations, culminating in a fully 
integrated, flight-like vehicle configuration. At each level, it is implied that the system-level analyses are updated to include models reflecting the best information available from each sub-system by incorporating new test and analysis results. Necessary sub-system models include aerodynamic and aerothermodynamic databases, models for propulsion system performance and sizing, and GN\&C algorithms. TRL 6 is the target development level for adoption on a robotic-scale flight demonstration project at Mars, and accordingly, is the terminus for the integrated systems roadmap presented below.

TRL 1 and 2 have been largely satisfied through the use of 3-DOF trajectory simulations to define top-level requirements, estimate operational envelopes, and demonstrate the potential benefits of SRP for Mars EDL.,6,7 Theoretical models have been used to perform first-order sizing with acceptable volume and mass margins, within a notional EDL system, and to demonstrate system sensitivities to SRP performance. Achievement of TRL 3 will require increased analysis fidelity in sub-system modeling and integrated system analysis to demonstrate full-scale vehicle performance with model uncertainties and acceptable packaging margins (system mass, volume, and mass distribution) using 3- and 6-DOF simulations.

The achievement criteria for TRL 4 are the first ones concerned with the direct integration of SRP sub-systems and subsequent integration of the SRP components into a full-scale vehicle. It is recommended that one or two flight-like vehicle configurations be selected with preliminary mechanical designs completed for the integrated SRP system and aeroshell structure. Simulation capability will be extended to 6-DOF Monte Carlo analysis and shall include off-nominal operating conditions, as well as models for transients during SRP engine startup, throttling, and shutdown. Acceptable margins must be demonstrated on mass, volume, and critical hardware clearances.

Achievement of TRL 5 will require moving beyond simulations to operation under relevant environmental conditions and is likely to be the most intensive stage in maturing SRP into a viable decelerator technology. Individual sub-systems will be brought together at the integrated system level, and ground testing of flight-like systems and flight-testing of sub-scale configurations at Earth will be initiated. All critical systems and interfaces for the "best" vehicle configuration will be sized and packaged in mechanical detail. Acceptable performance with all uncertainties (e.g. landing accuracy and altitude, timeline) and acceptable margins for the integrated system (e.g. aerodynamic, thermal, and structural) will be demonstrated using 6-DOF Monte Carlo analyses and validated computational models, respectively. A sub-scale hot fire test of a flight-like propulsion system and controller will be conducted, with simulated flight dynamics, through initiation, dynamic throttling, and shutdown. Preliminary requirements for a series of sub-scale atmospheric flight tests at Earth will be defined, with supporting simulation and modeling capabilities developed. Two flight tests will be conducted as part of achieving TRL 5, as described below. These flight tests follow the rationale of progressively increasing the level of sub-system integration towards a fully integrated, flight-viable configuration. TRL 5 will be achieved after post-flight analysis agrees acceptably with measured flight test data.

Achievement of TRL 6 will require successful demonstration of an EDL system prototype utilizing SRP under relevant environmental conditions. A sub-scale hardware mock-up will be built to demonstrate successful packaging and integration as predicted by analytical models. EDL trajectory simulation "stress cases" will be developed to demonstrate the survivability of the vehicle to off-nominal conditions. Integrated thermal and structural analysis will demonstrate system tolerance to thermal conditions during the SRP burn duration (e.g. plume impingement and engine soak back). A third, and final, flight test at Earth will be conducted using flight-like throttleable engines and closed-loop stable GN\&C from engine startup through simulated landing, with post-flight analysis completed and agreeing acceptably with measured flight test data. Achievement of TRL 6 will indicate that the performance and integration of SRP, as part of a flight-like EDL system, have been acceptably verified and validated through simulation and testing and that SRP has been matured into a viable technology option for roboticscale flight demonstration at Mars.

\section{Flight Testing}

The roadmap presented here is based on an aggressive schedule for advancing SRP through TRL 6, with a goal of sub-scale Earth atmosphere flight tests by 2016. It is expected that flight tests will be critical to advancing SRP through TRLs 5 and 6 where integrated system performance must be demonstrated in a relevant environment. This early flight-testing will play a critical role in accurately understanding the integration and performance of SRP component technologies by helping to test transient conditions, which are difficult to simulate in a wind tunnel or 
model with CFD. Flight tests will also help to validate analytical models and confirm sub-scale test data from ground-based testing. Furthermore, early flight tests will help to characterize the performance metrics described in the following section by providing data in a relevant free-flight environment.

Depending on the level of acceptable risk, the use of SRP on a precursor robotic-scale Mars mission may require an Earth-based qualification flight. Prior to a qualification flight test, multiple sub-scale flight tests throughout the development cycle are planned to rapidly increase the knowledge base for SRP performance and dynamic behavior. Three flight tests are proposed to mature integrated SRP technology through TRLs 5 and 6 , with increasingly flightlike systems in each successive test. The top-level progression of flight test architectures is:

- Flight Test 1: Non-throttleable engines, passively stabilized entry vehicle, "proof-of-concept" test

- Flight Test 2: Throttleable engines, passively stabilized entry vehicle

- Flight Test 3: Throttleable engines, closed-loop GN\&C representative of full-scale, parameter identification

These flight tests will be designed to match relevant scaling parameters and expected conditions on Mars, with a primary focus on Mach and dynamic pressure matching. The first flight test will allow the system to achieve TRL 5 by demonstrating SRP performance in a relevant environment. Based on data from this first test, the following tests will be able to have more flight like characteristics such as throttleability and control, which will mature the technology to TRL 6 .

To date, there are two leading candidates for potential venues for SRP flight tests at Earth. ${ }^{15}$ One is a sounding rocket platform and the other is a balloon-launched, rocket-accelerated platform similar to that used for the Viking parachute testing. ${ }^{16}$ Each of these venues, as well as other potential platforms, will be considered and evaluated based on the ability to meet specific requirements for each test. The mission design concept for the Sounding Rocket SRP Test (SRST) is shown in Figure 5. In this concept, the SRP test article is stacked atop a two-stage rocket for the launch/ascent and coast phases. Prior to reentry, the first two stages are separated, and a nose cone, which protects the payload during ascent, is jettisoned. The test phase begins upon reentry via a dynamic pressure trigger when the SRP system is ignited.

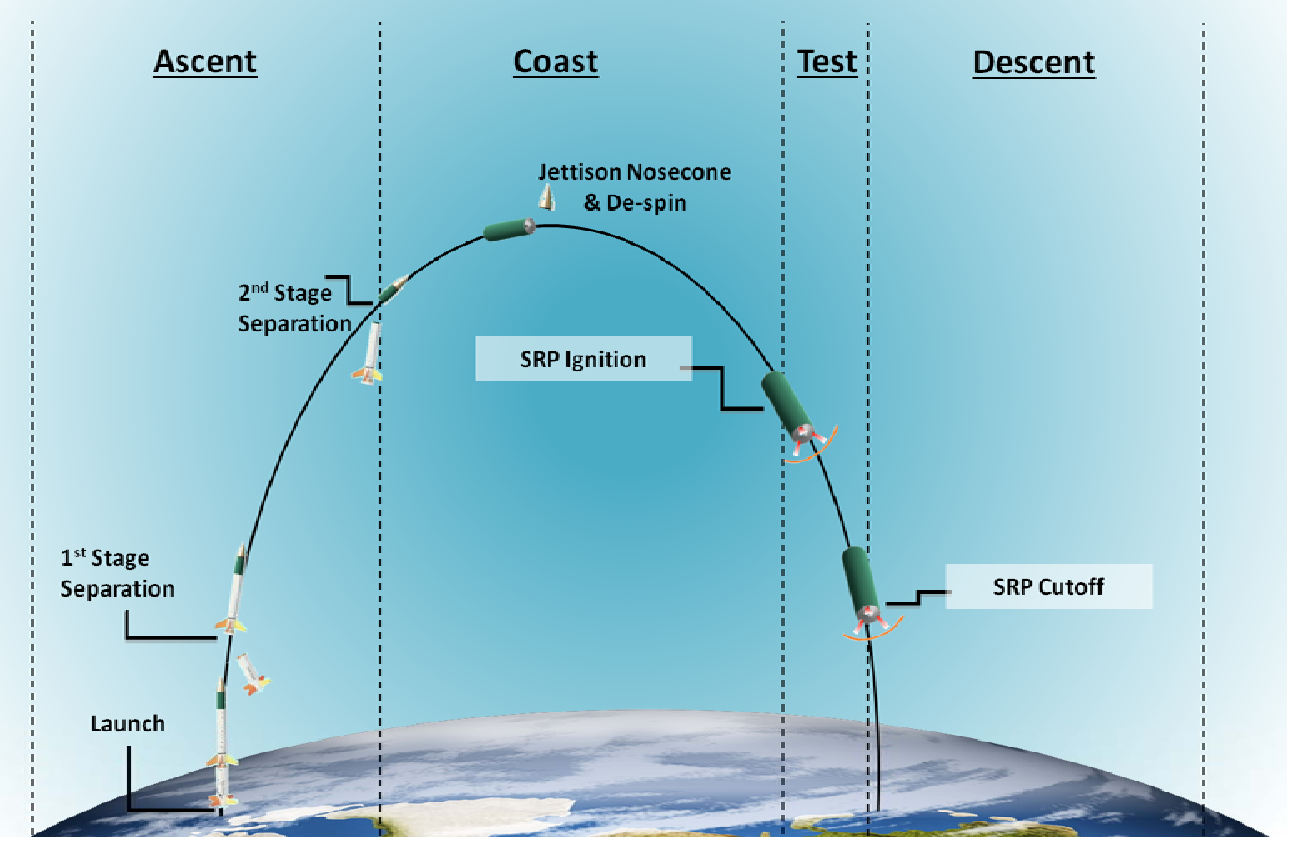

Figure 5. Concept of Operations for the Sounding Rocket SRP Test ${ }^{15}$ 


\section{The Balloon Launched SRP Test (BLST) concept is divided into 5 mission phases: loft, boost, coast, test, and descent. The concept of operations is shown in}

Figure 6. During the loft phase, the test article is suspended beneath a large balloon. Upon achieving an acceptable staging condition (altitude, position, and azimuth), the test article is released from the balloon. This marks the transition from the loft phase to the boost phase. The boost phase begins with one second of freefall during which spin-up motors are utilized to spin stabilize the test article prior to ignition of the boost propulsion system. Once spin-up is complete, the boost propulsion system is initiated to bring the test article to desired test conditions. A brief coast phase follows burnout of the boost motors. This quiescent period allows for any residual thrust transients to die out. The test phase is initiated following the coast phase by igniting the test propulsion system. After conclusion of the test phase, the descent phase begins. Depending on the need for recovery, combined with range safety considerations, the test article would either descend safely under parachute or continue unguided to the surface. In either case, all data would be transmitted prior to impact.

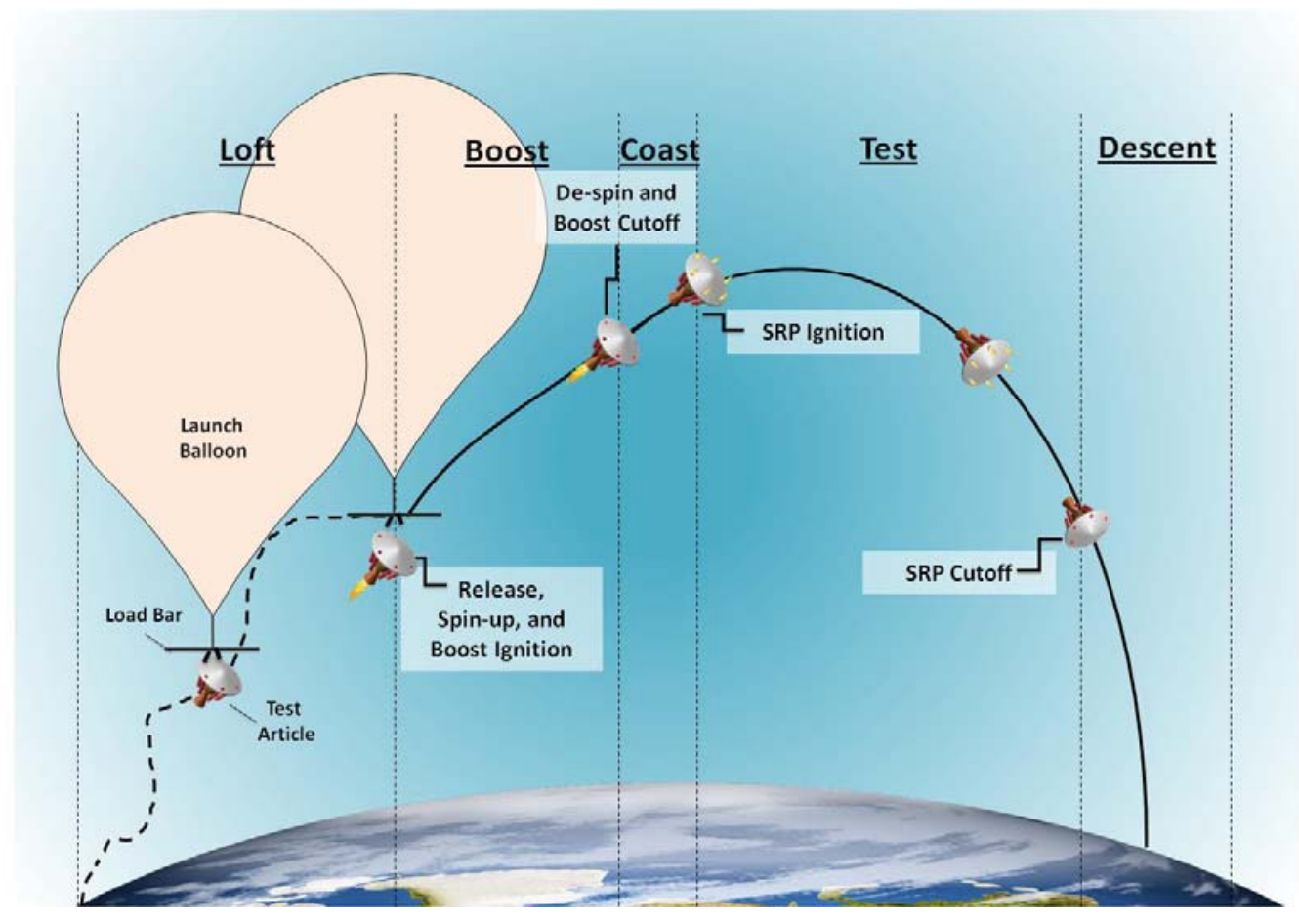

Figure 6. Concept of Operations for the Balloon Launched SRP Test ${ }^{15}$

Preliminary concept exploration to examine the capabilities of each launch platform has been performed and is summarized 
Table 4. In general, the BLST platform is much more capable in terms of vehicle scale, system mass, instrument accommodation, test duration, and trajectory flexibility. This increased performance comes at significantly higher costs and a longer development cycle. In contrast, a sounding rocket test could be performed at reduced cost with a compressed schedule, subject to a substantial reduction of flexibility in test article and test trajectory design. 
Table 4. Comparison Between Potential SRP Flight Test Venues ${ }^{15}$

\begin{tabular}{|c|c|c|}
\hline \hline Platform & Sounding Rocket & Balloon \\
\hline Test Duration (sec) & $12-16$ & $>100$ \\
\hline Development Time (months) & $9-18$ & $18-36$ \\
\hline Instrumentation & 250 Pressure \& Temperature Sensors & $>1000$ Pressure \& Temperature Sensors \\
\hline Test Article Diameter $(\mathrm{m})$ & $\leq 0.43 \mathrm{~m}$ & Variable, up to $\sim 4 \mathrm{~m}$ \\
\hline \hline
\end{tabular}

Detailed test requirements for each of the three proposed flight tests must be developed before the test venues can be adequately traded against each other. Key requirements include target trajectory envelopes (e. g. Mach number and dynamic pressure) and test durations, allowable trajectory dispersions, desired propellant combinations and thrust profiles, flight configuration definitions, required test data and associated instrumentation, ground support requirements, and range safety considerations. As these requirements are developed, the ability of each platform to meet them can be determined. A progressive flight test series is envisioned, where each flight test relies heavily on, and adapts minimally from, the design of the previous flight test. As such, a single, unifying test venue across all three tests is desirable. This desire must be traded against cost, schedule, and the ability of each venue to meet the specific requirements for each flight test.

\section{Key Performance Parameters}

The TRL scale provides a quantitative, high level definition of the steps NASA follows for maturing technologies to flight readiness. Definition of the levels depends on the technology in question and is open to interpretation depending on the intended purpose. NASA has established additional guidelines to provide a more quantifiable assessment of a technology's maturity: Key Performance Parameters (KPPs). As defined by NASA, ${ }^{17}$ KPPs are "those capabilities or characteristics (typically engineering-based or related to safety or operational performance) considered most essential for successful mission accomplishment. Failure to meet a KPP threshold can be cause for the project, system, or advanced technology development to be reevaluated or terminated or for the system concept or the contributions of the individual systems to be reassessed." Each KPP requires two levels of technical maturity: a threshold and a goal. The threshold level defines the minimum acceptable performance metric that the technology must provide in order to successfully meet mission requirements. The goal level, which usually exceeds the threshold, defines the desired level of performance from the technology. Both the threshold and goal metrics must exceed the current state of the art in order to warrant investment in the technology. Proper definition of KPPs is critical to measuring technical maturity and guiding future investment decisions about the technology.

Table 5 lists the initial set of KPPs proposed to track the technical maturity of SRP. This list is considered to be an initial draft and will be continually updated as additional parameters are considered and requirements are refined. The current set of parameters was developed in consultation with the EDL-SA group and focuses on three areas: propulsion system performance and characteristics, GN\&C, and CFD capabilities. Performance parameters that are not currently achieveable are labeled as such. First and foremost, the SRP engines must provide enough thrust to decelerate the entry vehicle during descent (KPP 1). For human missions, the deceleration goal (4 Earth g's maximum) is limited by crew capabilities after transit from Earth to Mars. The second and third KPPs reflect the need for the SRP system mass fraction to be acceptably within the constraints of the overall EDL system mass. The threshold and goal levels were estimated from EDL-SA analysis. Additional engine-related KPPs are listed that cover reliable startup capability, thrust-to-weight ratio (T/W), throttling range, and specific impulse. As the development of EDL trajectory analysis tools matures, these KPPs will be refined as needed to reflect the desired performance requirements. 
Table 5. SRP Key Performance Parameters

\begin{tabular}{|c|c|c|c|c|c|}
\hline Number & Name & Description & State of the Art & Threshold & Goal \\
\hline 1 & $\begin{array}{c}\text { Maximum } \\
\text { Propulsive } \\
\text { Deceleration } \\
\end{array}$ & $\begin{array}{l}\text { Maximum propulsive } \\
\text { deceleration provided by } \\
\text { SRP, measured in Earth g's }\end{array}$ & N/A & 3 & 4 \\
\hline 2 & $\begin{array}{c}\text { System Dry Mass } \\
\text { Fraction }\end{array}$ & $\begin{array}{l}\text { SRP system dry mass, } \\
\text { measured as a fraction of } \\
\text { total entry vehicle mass at } \\
\text { SRP initiation }\end{array}$ & TBD & 0.25 & 0.20 \\
\hline 3 & $\begin{array}{l}\text { Fuel Mass } \\
\text { Fraction }\end{array}$ & $\begin{array}{l}\text { Fuel mass for SRP, } \\
\text { measured as a fraction of } \\
\text { total SRP system wet mass }\end{array}$ & $0.1+0.06 *$ Mach & $<0.1+0.05 *$ Mach & $<0.1+0.04 *$ Mach \\
\hline 4 & $\begin{array}{l}\text { Engine Startup } \\
\text { Capability }\end{array}$ & $\begin{array}{l}\text { Ability of SRP system to } \\
\text { start in the expected } \\
\text { environments (Mach } \\
\text { number and back pressure at } \\
\text { initiation) }\end{array}$ & N/A & $\begin{array}{c}\text { Mach }<=3 \\
\text { Back pressure }<=0.75 \\
\text { psi }\end{array}$ & $\begin{array}{c}\text { Mach }<=5 \\
\text { Back pressure }<=1.5 \\
\text { psi }\end{array}$ \\
\hline 5 & Engine $T / W$ & $\begin{array}{l}\text { Ratio of maximum thrust } \\
\text { and weight of a single } \\
\text { engine }\end{array}$ & 70 & 80 & 90 \\
\hline 6 & $\begin{array}{l}\text { Engine } \\
\text { Throttling }\end{array}$ & $\begin{array}{l}\text { Minimum thrust of a single } \\
\text { engine via throttling, } \\
\text { measured as a percentage of } \\
\text { maximum thrust }\end{array}$ & $50 \%$ & $33 \%$ & $20 \%$ \\
\hline 7 & $\begin{array}{c}\text { Engine Specific } \\
\text { Impulse }\end{array}$ & $\begin{array}{l}\text { Specific impulse of a single } \\
\text { engine }\end{array}$ & $350 \mathrm{~s}$ & $370 \mathrm{~s}$ & $380 \mathrm{~s}$ \\
\hline 8 & Vehicle Stability & $\begin{array}{l}\text { Ability of system to provide } \\
\text { a closed-loop stable entry } \\
\text { vehicle, measured as control } \\
\text { gain \& phase margins }\end{array}$ & N/A & $\begin{array}{c}\text { Gain margin }=4 \mathrm{~dB} \\
\text { Phase margin }=30 \mathrm{deg}\end{array}$ & $\begin{array}{c}\text { Gain margin }=6 \mathrm{~dB} \\
\text { Phase margin }=45 \mathrm{deg}\end{array}$ \\
\hline 9 & $\begin{array}{c}\text { Vehicle } \\
\text { Controllability }\end{array}$ & $\begin{array}{l}\text { Ability of SRP system (and } \\
\text { RCS) to provide the } \\
\text { required maximum entry } \\
\text { vehicle attitude rates and } \\
\text { accelerations }\end{array}$ & N/A & $\begin{array}{c}\text { Max. rate }=15 \mathrm{deg} / \mathrm{s} \\
\text { Max. acceleration = 5 } \\
\text { deg/s2 }\end{array}$ & $\begin{array}{c}\text { Max. rate }=30 \mathrm{deg} / \mathrm{s} \\
\text { Max. acceleration }=10 \\
\text { deg/s2 }\end{array}$ \\
\hline 10 & $\begin{array}{l}\text { CFD Pressure } \\
\text { Prediction }\end{array}$ & $\begin{array}{l}\text { Accuracy of CFD surface } \\
\text { pressure coefficient due to } \\
\text { SRP plume interference, } \\
\text { measured as a difference } \\
\text { from ground/flight test data }\end{array}$ & 0.2 & 0.15 & 0.1 \\
\hline 11 & $\begin{array}{l}\text { CFD Force } \\
\text { Prediction }\end{array}$ & $\begin{array}{l}\text { Accuracy of CFD total axial } \\
\text { and normal forces } \\
\text { (aerodynamic }+ \text { propulsive), } \\
\text { measured as a percentage } \\
\text { difference from } \\
\text { ground/flight test data }\end{array}$ & $\begin{array}{l}C_{A}-25 \% \\
C_{N}-0.2\end{array}$ & $\begin{array}{l}C_{A}-20 \% \\
C_{N}-0.15\end{array}$ & $\begin{array}{c}C_{A}-15 \% \\
C_{N}-0.1\end{array}$ \\
\hline 12 & $\begin{array}{l}\text { CFD Moment } \\
\text { Prediction }\end{array}$ & $\begin{array}{l}\text { Accuracy of CFD total pitch } \\
\text { and yaw moments } \\
\text { (aerodynamic }+ \text { propulsive), } \\
\text { measured as a percentage } \\
\text { difference from } \\
\text { ground/flight test data }\end{array}$ & $50 \%+/-0.02$ & $40 \%+/-0.015$ & $30 \%+/-0.01$ \\
\hline 13 & $\begin{array}{l}\text { CFD Heat Flux } \\
\text { Prediction }\end{array}$ & $\begin{array}{l}\text { Accuracy of CFD models in } \\
\text { predicting surface heat flux } \\
\text { due to SRP plume } \\
\text { interference, measured as a } \\
\text { percentage difference from } \\
\text { ground/flight test data }\end{array}$ & $50 \%$ & $40 \%$ & $30 \%$ \\
\hline
\end{tabular}


The next two KPPs ( 8 and 9) address the need to develop an SRP system that can control and stabilize the entry vehicle in an environment influenced by the interactions between the engine plumes, freestream flow, and entry vehicle. The vision for the SRP system is that it will be used, perhaps along with a secondary RCS, to fly the entry vehicle at angle-of-attack with a higher $L / D$ than is capable with Viking aeroshells $(L / D=0.24$ for MSL). The additional lifting capability will allow the entry system to reach a pre-determined landing site with sufficient accuracy by canceling out entry dispersions, such as those caused by atmospheric density uncertainties, that would otherwise result in larger landing footprints. The ability of the SRP system (and RCS) to control and stabilize the entry vehicle requires advancements of control algorithms in concert with a better understanding of the influence of complex SRP flow physics on the entry vehicle aerodynamics.

The remaining KPPs (10 through 13) address the advancement of the Navier-Stokes CFD methods needed to build aerodynamics and aerothermodynamics databases for entry trajectory analyses. SRP plume impingement on the entry vehicle will generate unwanted forces and moments that must be damped by the control system. Knowledge of those forces and moments will come from wind tunnel tests whose main objectives are to better understand the flow physics for a range of SRP conditions (Mach, $\mathrm{C}_{\mathrm{T}}$, angle-of-attack, etc.) and provide data with which to validate CFD methods. CFD codes and methods proven for SRP will be a critical element of full-scale entry system performance predictions. Preliminary work has been completed to compare various CFD codes to subscale wind tunnel tests in perfect gas air and different SRP jet gases. Promising results have been recently demonstrated, ${ }^{9,10}$ but significant work is still needed in the areas of wind tunnel testing and CFD code development to address current shortcomings. As the potential applications for SRP continue to evolve, additional KPPs will be formulated to address areas such as mission safety and reliability, touchdown dynamics, and abort/divert capabilities.

\section{Roadmap Schedule}

\section{After identifying the various TRL achievement criteria for each SRP component technology, the ETDP team developed an aggressive schedule in response to NASA's new emphasis on Mars technology demonstration projects.}

Figure 7 shows one such roadmap of the major analyses, ground tests, and Earth flight tests to mature SRP for use on a robotic-scale (1-3 metric tons) precursor demonstration mission at Mars by the late 2010s or early 2020s. The current thinking is that multiple Earth flight tests must be achieved 3-4 years prior to adoption on a Mars flight demonstration project. The dates and sequence of events shown in

Figure 7 are flexible and will undoubtedly change as NASA evolves its EDL technology investment plans.

\section{The roadmap focuses on the major testing and analysis tasks envisioned for the various technology components through TRLs 5 and 6. The timing of the TRL progression shown in}

Figure 7 is notional and reflects an overall assessment of how technical maturity might progress. First and foremost, early engine testing in a supersonic flow must be conducted to demonstrate successful startup and throttling using available ground facilities capable of engine testing. Analytical modeling, including CFD, must progress in conjunction with hardware development in order for SRP to mature. Validated models will be needed to bridge the gap between ground facility capabilities and full-scale Mars conditions. Therefore, it is recommended that the initial work also focus on wind tunnel testing designed to provide data for CFD aerodynamics and aerothermodynamics validation exercises. The wind tunnel models will progress from generic geometries to configurations identified for Earth flight-testing and full-scale Mars systems. At each step, CFD must be shown to accurately predict aerodynamics and aerothermodynamics to the levels required by the KPPs.

The integrated vehicle-level analysis should be initiated with clear definition of performance requirements for full-scale Mars systems. All models required to support 3- and 6-DOF entry trajectory analyses (mass, aerodynamics, GN\&C) must be developed and continuously improved in fidelity using the best available test data. Design cycles are envisioned during which model complexity increases for a narrowing set of SRP configurations, resulting in a "best" vehicle design. Each design cycle will require CFD-based aerodynamic and aerothermodynamic databases to support entry trajectory analysis and TPS design. A development unit is included after the final design cycle to demonstrate successful packaging of the SRP system as predicted by models. 
Achievement of TRLs 5 and 6 will require Earth flight-testing of gradually more complex SRP systems.

Possible venues for such tests include sounding rockets or balloons with rocket assist. The progression of three flight tests shown in

Figure 7 reflects the current thinking that the first demonstration at Mars will have a payload at least as large as MSL's. The first fight test is envisioned as focusing more on successful engine startup and achieving the predicted $\Delta \mathrm{V}$ with a passively stabilized vehicle. The second and third tests add throttled engines and closed-loop GN\&C, respectively, both of which will be required on a full-scale vehicle. Each flight test vehicle will need to be instrumented sufficiently to validate the performance models. Also, the final flight test vehicle will need to be of sufficient size to retire scalability risks for Mars application. The flight-test phase of SRP development is likely to make up a large percentage of the total development costs; estimates are in preparation to determine the investment required to execute flight tests of sufficient scale and complexity in the time frame needed.

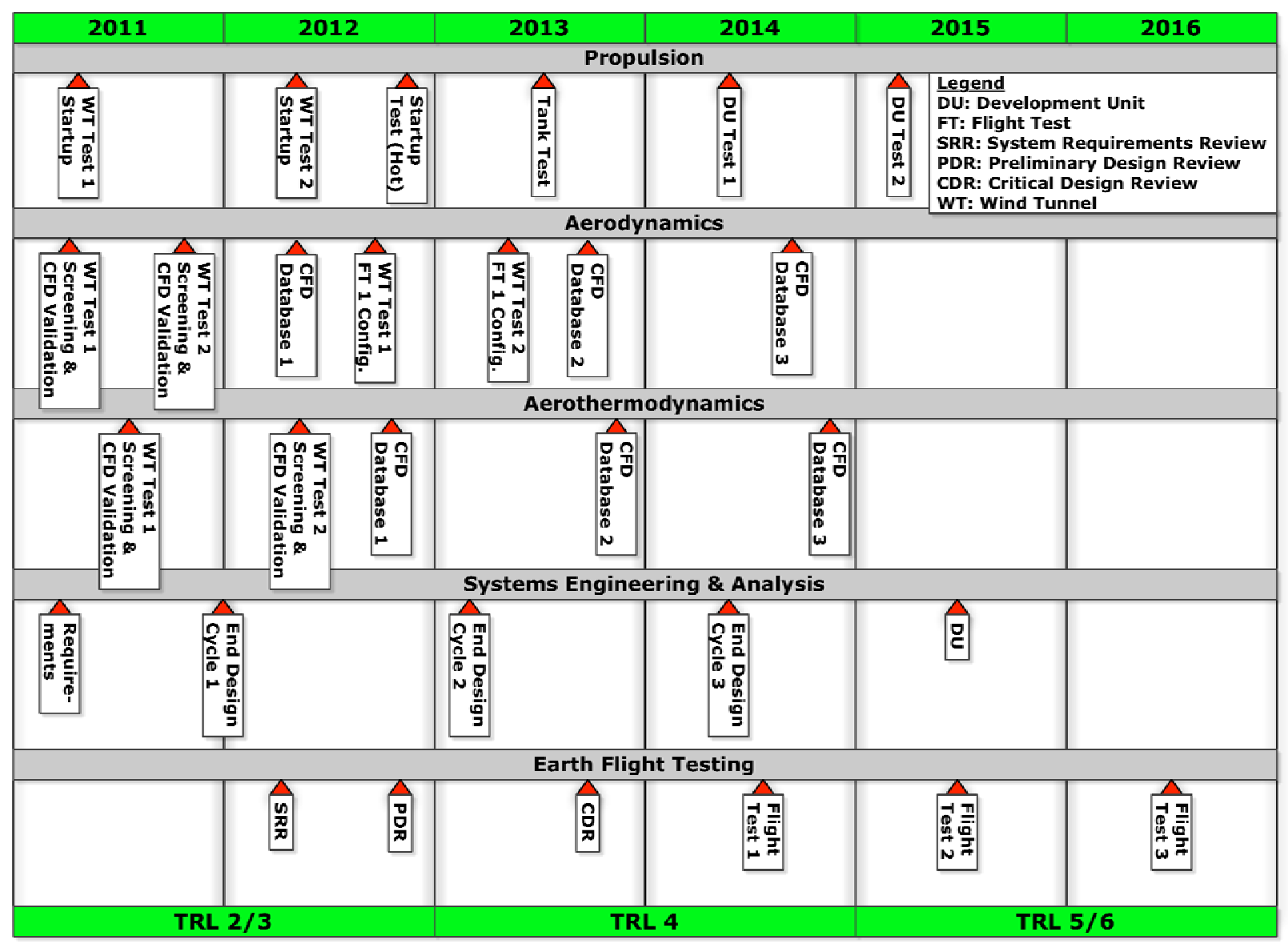

Figure 7. Accelerated Technology Maturation Schedule to Achieve TRL 6 for Robotic Scale SRP 


\section{Summary and Conclusions}

Mars atmospheric entry systems based on those used for the Viking missions in the 1970s (blunt aeroshell and supersonic parachute) are nearing their practical limit of landed payload mass with the upcoming Mars Science Laboratory (launch in 2011, < 1 metric ton). Consequently, NASA is investing in revolutionary entry system technologies that will allow the human exploration of Mars with larger payloads (10s of metric tons), improved landing accuracy, and higher landing site altitudes. Supersonic Retro-Propulsion (SRP) using chemical rockets is one deceleration technology that is viewed by NASA as enabling for human-scale Mars missions. NASA last considered SRP as a candidate entry system technology in the 1970s before the Viking missions, focusing on the aerodynamic trends and benefits via sub-scale wind tunnel tests.

NASA's renewed interest in SRP has led to initial investments focusing on performance requirements and parametric sizing analyses that indicate the potential benefits of SRP for human-scale payloads. The Exploration Technology Development Program (ETDP) has taken on the task of starting to define how best to advance the various SRP technology components (propulsion, aerodynamics/aerothermodynamics, flight mechanics, integrated vehicle engineering/analysis) beyond their current state and how to demonstrate prototype system performance through Earth-based flight tests. Towards these goals, the ETDP team has identified analytical and experimental achievement criteria for SRP based on NASA guidelines for technology maturation. Technologies requiring significant investment and technical advancement for SRP include: high-thrust engines (100s of $\mathrm{kN}$ ) capable of starting and throttling against a supersonic flow, computational fluid dynamics (CFD) tools for predicting aerodynamics and aerothermodynamics validated with wind tunnel data, algorithms for maintaining entry vehicle stability and control, entry vehicle design (packaging, structural, thermal), and trajectory simulations. Significant improvements in modeling capabilities, especially in the area of aerodynamic/propulsive interactions, will be needed to predict full-scale vehicle performance and show acceptable margins with confidence.

Multiple ground test campaigns will be needed to demonstrate the required engine performance and provide data for CFD model validation. In order to begin SRP flight demonstrations at Mars in the next 10 years, it is recommended that NASA invest early in engine ground tests that demonstrate acceptable performance in a supersonic opposing flow and sub-scale wind tunnel tests that provide data for CFD validation exercises across a range of parameters (Mach number, thrust coefficient) and configurations. Concurrently, integrated vehicle level analyses will be needed to define the expected SRP operating conditions and demonstrate acceptable performance margins. Finally, a series of Earth-based flight tests is needed to advance SRP to a level where the risks are acceptably reduced and system performance is demonstrated to be scalable to Mars conditions as predicted by validated models. The expectation is that the final flight test at Earth will incorporate multiple SRP engines and a closed-loop control system on an entry vehicle of sufficient scale that performs in conditions that are relevant to

those at Mars. Cost estimates for the flight test program will be developed to determine the investment level needed for accelerated development of SRP for robotic scale Mars missions. 


\section{References}

${ }^{1}$ Braun, R. D., and Manning, R. M., "Mars Exploration Entry, Descent and Landing Challenges," Journal of Spacecraft and Rockets, Vol. 44, No. 2, March-April 2007.

${ }^{2}$ Zang, T. A. (Editor), "Entry, Descent and Landing Systems Analysis Study: Phase 1 Report," EDL Systems Analysis Team, NASA TM-2010-0000002009, May 2010.

${ }^{3}$ Jarvinen, P. O., and Adams, R. H., "The Aerodynamic Characteristics of Large Angled Cones with Retrorockets," NASA CR NAS 7-576, February 1970.

${ }^{4}$ Korzun, A. M, Braun, R. D., and Cruz, J. R., "Survey of Supersonic Retropropulsion Technology for Mars Entry, Descent, and Landing," Journal of Spacecraft and Rockets, Vol. 46, No. 5, September-October 2009, pp. 929-937.

${ }^{5}$ Drake, B. G. (Editor), "Human Exploration of Mars, Design Reference Architecture 5.0," Mars Architecture Steering Group, NASA Headquarters, NASA SP-2009-566, July 2009.

${ }^{6}$ Korzun, A. M., and Braun, R. D., "Performance Characterization of Supersonic Retropropulsion for Application to HighMass Mars Entry, Descent, and Landing," AIAA Paper 2009-5613, AIAA Atmospheric Flight Mechanics Conference, Chicago, Illinois, 10-13 August 2009.

${ }^{7}$ Steinfeldt, B. A., Theisinger, J. E., Korzun, A. M., Clark, I. G., Grant, M. J., and Braun, R. D., "High Mass Mars Entry, Descent, and Landing Architecture Assessment," AIAA Paper 2009-6684, AIAA SPACE 2009 Conference and Exposition, Pasadena, California, 14-17 September 2009.

${ }^{8}$ Mankins, J. C., "Technology Readiness Levels: A White Paper," NASA Office of Space Access and Technology, Advanced Concepts Office, April 1995.

${ }^{9}$ Trumble, K. A., Kleb, W., Carlson, J.-R., Buning, P., Edquist, K. T., Schauerhamer, D. G., and Barnhardt, M. D., “An Initial Assessment of Navier-Stokes Codes Applied to Supersonic Retro-Propulsion," AIAA Paper 2010-5047, 10 ${ }^{\text {th }}$ AIAA/ASME Joint Thermophysics and Heat Transfer Conference, Chicago, IL, 30 June-1 July, 2010.

${ }^{10}$ Korzun, A. M., Cordell, Jr., C. E., and Braun, R. D., "Comparison of Inviscid and Viscous Aerodynamic Predictions of Supersonic Retropropulsion Flowfields," AIAA Paper 2010-5048, $10^{\text {th }}$ AIAA/ASME Joint Thermophysics and Heat Transfer Conference, Chicago, IL, 30 June-1 July, 2010.

${ }^{11}$ Scallion, W. I., "Space Shuttle Reaction Control System - Flow Field Interaction During Entry," Proceedings of the NASA Aerodynamics Symposium, Williamsburg, Virginia, 27-30 April 1993.

${ }^{12}$ Dyakonov, A. A., Glass, C. E., Desai, P. N., and Van Norman, J. W., "Analysis of Effectiveness of Phoenix Entry Reaction Control System", AIAA Paper 2008-7220, AIAA/AAS Astrodynamics Specialist Conference and Exhibit, Honolulu, Hawaii, 1821 August 2008.

${ }^{13}$ Dyakonov, A. A., Schoenenberger, M., Scallion, W. I., Van Norman, J. W., Novak, L. A., and Tang, C. Y., "Aerodynamic Interference Due to MSL Reaction Control System", AIAA Paper 2009-3915, 41 ${ }^{\text {st }}$ AIAA Thermophysics Conference, San Antonio, Texas, 22-25 June 2009.

${ }^{14}$ Dyakonov, A. A., Buck, G. M., and Decaro, A. D., "Analysis of Aeroheating Augmentation Due to Reaction Control System Jets on Orion Crew Exploration Vehicle”, AIAA Paper 2009-3844, 41 ${ }^{\text {st }}$ AIAA Thermophysics Conference, San Antonio, Texas, 22-25 June 2009.

${ }^{15}$ Kipp, D. M., Bahrami, P., Brown, J. D., De Jong, C. D., Guernsey, C., Post, E., Prakash, R., Sklyanskiy, E., Strauss, W., and Chen, G. T., "Flight Test Concept Exploration for Supersonic Retro-Propulsion Development," JPL D-63889, Jet Propulsion Laboratory, California Institute of Technology, 29 October 2009.

${ }^{16}$ Lundstrom, R., Raper, J., Bendura, R., and Shields, E., "Flight Tests of Viking Parachute System in Three Mach Number Regimes, Vol. 1,"NASA TN D-7692, October 1974.

17 "NASA Systems Engineering Processes and Requirements w/Change 1 (11/04/09)," NPR 7123.1A, NASA Office of the Chief Engineer, 26 March 2007. 